\title{
PENGEMBANGAN PERANGKAT PEMBELAJARAN IPA BERBASIS KEARIFAN LOKAL UNTUK MENINGKATKAN HASIL BELAJAR KOGNITIF SISWA
}

\author{
Siti Halimah Khaerani ${ }^{1}$, Septiana Dwi Utami ${ }^{2}$, Saidil Mursali ${ }^{3}$ \\ ${ }^{1}$ Program Studi Pendidikan Biologi FPMIPA IKIP Mataram \\ e-mail: halimahhaerani@gmail.com \\ ${ }^{2}$ Program Studi Pendidikan Biologi FPMIPA IKIP Mataram \\ e-mail: septianadwiutami@ikipmataram.ac.id \\ ${ }^{3}$ Program Studi Pendidikan Biologi FPMIPA IKIP Mataram \\ e-mail: saidilmursali@ikipmataram.ac.id
}

Submit: 08-06-2020 Revisi: 27-06-2020 Diterima: 08-07-2020 Diterbitkan: 17-08-2020

\begin{abstract}
Abstrak: Pengintegrasian potensi lokal dalam pembelajaran di sekolah masih sangat kurang terutama pada pelajaran IPA. Penelitian ini bertujuan menghasilkan perangkat pembelajaran IPA berbasis kearifan lokal yang layak untuk meningkatkan hasil belajar kognitif siswa. Penelitian ini merupakan penelitian pengembangan yang menggunakan model 4-D. Uji coba penelitian menggunakan one group pre-test and post-test design. Instrumen penelitian meliputi lembar validasi, pengamatan keterlaksanaan pembelajaran, tes hasil belajar, dan angket respon siswa. Data hasil validasi, keterlaksanaan pembelajaran dan angket dianalisis secara deskriptif kualitatif; sedangkan data tes hasil belajar dianalisis berdasarkan ketuntasan individu dan n-gain. Hasil penelitian menunjukkan bahwa perangkat pembelajaran meliputi silabus dan RPP dalam kategori valid. Keterlaksanaan pembelajaran sebesar $87,65 \%$ dalam kategori sangat baik. Perolehan n-gain sebesar 0,64 dalam kategori sedang. Selain itu, skor respon siswa sebesar 3,6 dengan kategori sangat baik. Siswa memberikan respon yang positif terhadap proses pembelajaran yang telah dilakukan. Dengan demikian, perangkat pembelajaran IPA berbasis kearifan lokal termasuk layak digunakan untuk meningkatkan hasil belajar kognitif siswa.
\end{abstract}

Kata kunci: Hasil Belajar Kognitif, Kearifan Lokal, Perangkat Pembelajaran

\section{DEVELOPMENT OF SCIENCE TEACHING MATERIALS BASED ON LOCAL WISDOM TO ENHANCE STUDENT' COGNITIVE LEARNING OUTCOMES}

\begin{abstract}
Integrating local potential in learning in school is still lacking, especially in science lessons. This study aims to produce science learning materials based on local wisdom that is feasible to improve student cognitive learning outcomes. This research is a development study that uses a 4-D model. Research trials using one group pre-test and post-test. The research instruments included validation sheets, learning observations, learning outcomes tests, and response questionnaires. Validation data, learning outcomes, and questionnaires were analyzed descriptively qualitatively; while the learning outcomes data were analyzed based on individual completeness and n-gain. The results showed that the learning materials included syllabus and lesson plans in the valid category. The implementation of the learning plan is $87.65 \%$ in the very good category. Obtaining an n-gain value was 0.64 in the medium category. Also, the student response score was 3.6 with a very good category. Students gave positive responses to the learning process that has been done. Thus, science learning materials based on local wisdom are feasible to be used to improve student cognitive learning outcomes.
\end{abstract}

Keywords: Learning Outcomes, Local Wisdom, Science Learning Materials 
Khaerani, Utami, \& Musrsali. (2020). Pengembangan Perangkat Pembelajaran IPA Berbasis Kearifan Lokal untuk Meningkatkan Hasil Belajar Kognitif Siswa

\section{PENDAHULUAN}

Pendidikan nasional bertujuan untuk mengembangkan potensi peserta didik agar menjadi manusia Indonesia yang beriman dan bertakwa kepada Tuhan Yang Maha Esa, berakhlak mulia, sehat, berilmu, cakap, kreatif, mandiri, serta menjadi warga negara yang demokratis dan bertanggung jawab (Mannan, Sopyan, \& Sunarno, 2015). Tujuan pendidikan di atas sangat berkaitan dengan hakikat Ilmu Pengetahuan Alam (IPA). Hakikat IPA meliputi empat unsur utama; yaitu sikap, proses, produk, dan aplikasi. Keempat unsur ini mengharapkan peserta didik menjadi manusia yang kreatif. Oleh karena itu, keempat unsur IPA ini merupakan ciri IPA yang utuh yang tidak dapat dipisahkan satu sama lain. IPA juga berkaitan dengan proses mencari tahu tentang gejala alam secara sistematis; IPA bukanlah hanya penguasaan dari kumpulan pengetahuan yang berupa fakta-fakta, konsep-konsep, atau prinsip-prinsip saja tetapi juga merupakan suatu proses penemuan.

Pembelajaran IPA diharapkan menjadi wahana bagi peserta didik untuk mempelajari diri sendiri dan alam sekitar, serta prospek pengembangan lebih lanjut dalam menerapkannya dalam kehidupan sehari-hari (Depdiknas, 2006). Oleh karena itu, siswa seharusnya mampu melihat dan belajar melalui lingkungan yang ada di sekitarnya, misalnya seperti kearifan lokal yang terdapat di daerahnya masing-masing. Kearifan lokal yang dimiliki oleh suatu daerah merupakan ciri khas bagi daerah tersebut. Namun demikian, zaman sekarang ini banyak pemuda yang tidak menyadari potensi-potensi lokal daerahnya. Sebagian dari mereka lebih cenderung memilih untuk mencari pekerjaan di luar daerahnya. Hal ini menjadi masalah bagi dunia pendidikan di Indonesia karena ini membuktikan bahwa pendidikan IPA masih kurang terintegrasi dengan lingkungan sekitarnya, sehingga mereka cenderung tidak bisa mengenali potensi daerah mereka.

Berbagai potensi lingkungan sekitar siswa termasuk potensi sumber belajar yang layak untuk dimaksimalkan dalam pembelajaran IPA, misalnya lingkungan di desa Setiling. Desa Setiling adalah salah satu desa di kecamatan Batukliang Utara, Lombok tengah. Desa ini belum banyak dikenal oleh khalayak ramai. Desa ini masih termasuk desa yang asri dengan banyaknya pepohonan yang rindang di sekitar jalan dan udara yang sangat sejuk. Akan tetapi, bukan hanya khalayak ramai yang belum mengenal desa ini bahkan masyarakat desa ini sendiri masih banyak yang belum menyadari akan potensi daerah yang dimilikinya. Akibatnya, banyak wisatawan lokal maupun asing yang hanya tahu bahwa daerah wisata di Lombok Tengah hanya terdapat di desa Aik berik dan desa Aik bukak saja, padahal keasrian dari desa ini dapat dijadikan sebagai salah satu destinasi wisata alam Lombok dan juga dapat dijadikan model dalam pembelajaran yakni dengan mengikutsertakan potensi lokal desa ini ke dalam materi pelajaran atau menjadikannya sebagai baham ajar. Pengintegrasian potensi daerah ke dalam pembelajaran akan memberikan wawasan kepada siswa terkait potensi daerah dan nilai-nilai kearifan lokal (Wilujeng, 2016). Pengenalan potensi daerah dapat meningkatkan minat siswa terhadap potensi lokal di daerahnya, mengenal nilai-nilai kearifan lokal, dan mengalami internalisasi nilai yang mengantarkan siswa menjadi pribadi terpelajar dan berkarakter. Kenyataannya, masih banyak siswa di Indonesia yang memiliki nilai belajar kognitif yang rendah terutama dalam pelajaran IPA. Hasil survei TIMSS (Trends in International Mathematics and Science Study) tahun 2011 menunjukkan prestasi sains pelajar Indonesia menduduki posisi 40 dari 45 negara peserta (Martin et al., 2012). Hal ini dikarenakan kurangnya minat membaca peserta didik sehingga ketika mereka kesulitan dalam menyelesaikan permasalahan dalam kehidupan sehari-hari. Oleh karena itu, integrasi muatan lokal dalam pembelajaran IPA diharapkan mampu meningkatkan hasil belajar kognitif siswa.

Pengintegrasian muatan lokal dalam pembelajaran IPA sangat sesuai dengan Kurikulum 2013. Kurikulum 2013 menghendaki pengembangan pembelajaran IPA di SMP dalam konsep IPA terintegrasi atau IPA terpadu, di mana salah satu karakteristiknya adalah bersifat tematik. Potensi lokal sangat tepat dipilih sebagai dasar pemilihan tema, karena bersifat kontekstual, menarik, dan berkaitan dengan kehidupan nyata. Potensi lokal menyimpan konsep IPA asli yang berguna bagi kehidupan siswa dan masyarakat luas (Fitriani dkk., 2019; Suastra, Tika, \& Kariasa 2011). Hal ini sesuai dengan hasil penelitian Azizahwati dkk. (dalam Saputra dkk., 2016) bahwa pembelajaran berbasis kearifan lokal memberikan kesan yang kontekstual dalam pembelajaran dan siswa mudah memahami materi yang diajarkan. oleh karena itu tujuan peneliti adalah menghasilkan perangkat pembelajaran IPA berbasis kearifan lokal untuk meningkatkan hasil belajar kognitif siswa. Pembelajaran IPA berbasis kearifan lokal diyakini mampu meningkatkan hasil belajar kognitif siswa karena pembelajarannya sesuai dengan keadaan yang ada di lingkungan sekitarnya. 


\section{METODE PENELITIAN}

Penelitian ini dilaksanakan di MTs Nurussalam NW Lendang Doda, desa Barabali, Kecamatan Batukliang kabupaten Lombok Tengah di semester genap tahun ajaran 2017/2018. Jenis penelitian ini merupakan penelitian dan pengembangan (Research \& Develovment); yaitu berupa prosedur penelitian yang dilakukan dengan menciptakan suatu produk tertentu dan menguji keefektifan produk (Sugiyono, 2015). Produk dalam penelitian ini berupa perangkat pembelajaran (silabus dan RPP) berbasis kearifan lokal. Model pengembangan yang digunakan adalah model 4D seperti disajikan pada Gambar 1.

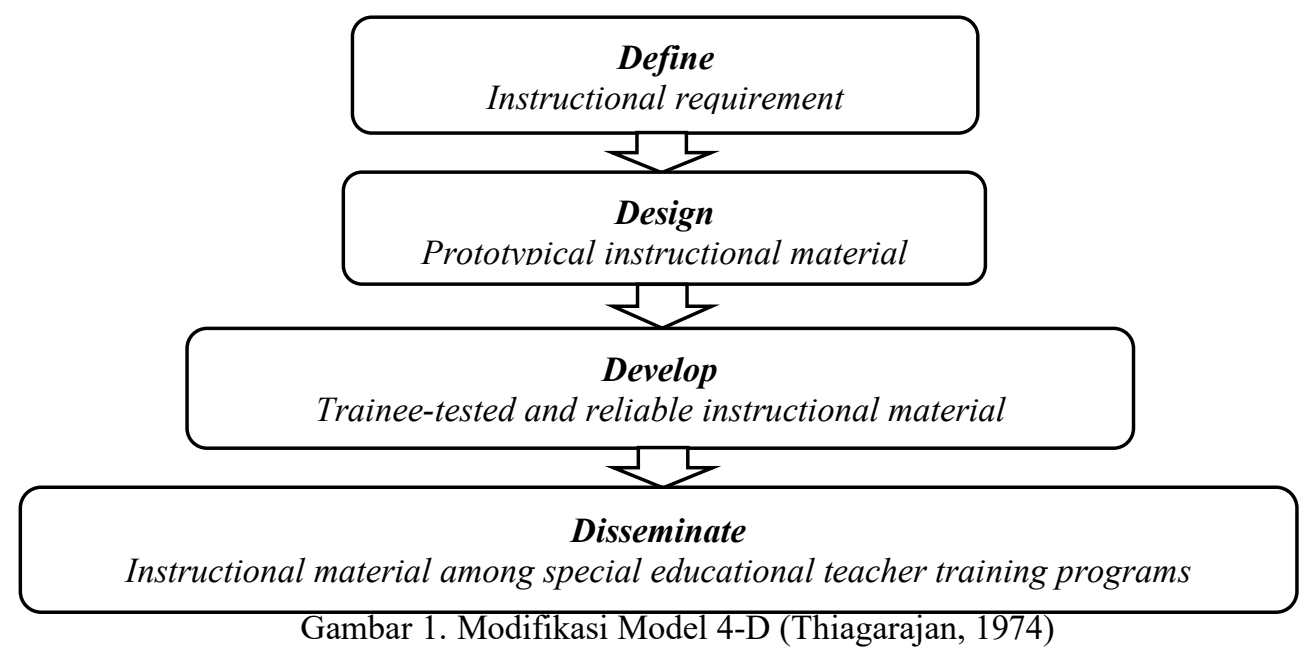

Uji coba kelas menggunakan one group pre-test and post-test design $\left(\mathrm{O}_{1} \mathrm{X} \mathrm{O}_{2}\right)$. Pembelajaran diawali dengan meminta siswa mengerjakan instrumen tes hasil belajar kognitif $\left(\mathrm{O}_{1}\right)$. Selanjutnya, guru melaksanakan pembelajaran IPA berbasis kearifan lokal selama 2 pertemuan (X). Selama proses pembelajaran, 2 pengamat menilai keterlaksanaan pembelajaran dengan menggunakan instrumen lembar pengamatan keterlaksanaan pembelajaran. Pada akhir penelitian, guru meminta siswa untuk mengerjakan kembali instrumen tes hasil belajar kognitif $\left(\mathrm{O}_{2}\right)$. Selain itu, siswa juga diminta mengisi instrumen angket respon berkaitan dengan tanggapan dari pelaksanaan pembelajaran yang telah diikutinya (Aisyah, 2016).

Data hasil validasi perangkat pembelajaran yang diberikan oleh ketiga validator dianalisis secara deskriptif kuantitatif, di mana rata-rata skor hasil validasi disesuaikan dengan kriteria: $3,25<$ sangat valid $\leq 4,00 ; 2,50<$ valid $\leq 3,25 ; 1,75<$ kurang valid $\leq 2,50 ;$ dan $1,00<$ tidak valid $\leq 1,75$. Data keterlaksanaan pembelajaran dan angket respon siswa dalam kegiatan pembelajaan juga dianalisis secara deskriptif kuantitatif, yaitu menghitung persentase jawaban untuk tiap-tiap pertanyaan yang diajukan. Sedangkan, untuk data pre-test dan post-test hasil belajar dihitung dengan rumus gain ternormalisasi dan hasilnya disesuaikan dengan kriteria $n$-gain pada Tabel 1.

\begin{tabular}{cc} 
Tabel 1. Kriteria Pengkategorian Gain Ternormalisasi \\
\hline Harga (\%) & Kriteria \\
\hline $\mathrm{g}<0,30$ & Rendah \\
$0,30 \leq \mathrm{g}<0,70$ & Sedang \\
$\geq 0,70$ & Tinggi \\
\hline Hake (1999) &
\end{tabular}

\section{HASIL DAN PEMBAHASAN}

Penelitian ini mengembangkan produk berupa perangkat pembelajaran IPA berbasis kearifan lokal untuk meningkatkan hasil belajar kognitif siswa. Perangkat yang dikembangkan berupa silabus dan RPP pada pokok bahasan interaksi antara mahluk hidup dengan lingkungan. Materi ini merupakan materi yang dibahas pada semester II untuk siswa kelas VII SMP/MTs. Kelayakan perangkat pembelajaran ditinjau dari hasil validitas perangkat, keterlaksanaan RPP, hasil belajar dan respon siswa. 
Khaerani, Utami, \& Musrsali. (2020). Pengembangan Perangkat Pembelajaran IPA Berbasis Kearifan Lokal untuk Meningkatkan Hasil Belajar Kognitif Siswa

\section{Validitas perangkat pembelajaran}

Dalam penlitian ini, menggambarkan kualitas isi dan konstruk dari silabus dan RPP yang dikembangkan berdasarkan penilaian validator. Hasil validasi perangkat pembelajaran disajikan pada Tabel 2.

Tabel 2. Hasil Validasi Perangkat Pembelajaran IPA Berbasis Kearifan Lokal

\begin{tabular}{|c|c|c|c|c|c|}
\hline \multirow{2}{*}{$\begin{array}{c}\text { Komponen Perangkat } \\
\text { Pembelajaran }\end{array}$} & \multicolumn{3}{|c|}{ Nilai Validator } & \multirow[t]{2}{*}{ Rata-rata } & \multirow{2}{*}{ Kriteria } \\
\hline & $\mathrm{I}$ & II & III & & \\
\hline Silabus & 3,50 & 3,00 & 3,30 & 3,20 & Valid \\
\hline RPP & 3,73 & 3,51 & 3,60 & 3,60 & Sangat valid \\
\hline
\end{tabular}

Berdasarkan Tabel 2; hasil validasi silabus dan RPP masing-masing sebesar 3,20 (kriteria valid) dan 3,60 (kriteria sangat valid). Berarti perangkat pembelajaran IPA berbasis kearifan lokal yang telah dikembangkan memenuhi kriteria validitas baik dari aspek isi maupun konstruknya. Hal ini didukung Widoyoko (2012) dan Ridwan (2007) bahwa perangkat dikatakan valid jika penilaian para validator terhadap seluruh aspek dari butir yang divalidasi memperoleh nilai $>2,5$ dengan kategori valid. Agar perangkat pembelajaran yang dikembangkan lebih berkualitas maka dilakukan revisi sesuai dengan saran validator sebagaimana disajikan pada Tabel 3.

Tabel 3. Saran Perbaikan Perangkat Pembelajaran IPA Berbasis Kearifan Lokal

\begin{tabular}{cll}
\hline \multirow{2}{*}{ Validator } & \multicolumn{3}{c}{ Sebelum Revisi } & \multicolumn{1}{c}{ Sesudah Revisi } \\
\cline { 2 - 3 } I & $\begin{array}{l}\text { Jenis penilaian diperbanyak, disesuaikan dengan } \\
\text { model pembelajaran yang digunakan }\end{array}$ & Jenis penilaian sudah ditambahkan. \\
\cline { 2 - 3 } & Integrasi antara KI dan KD tidak tampak. & KI dan KD disesuaikan dengan format K-13 \\
\cline { 2 - 3 } & $\begin{array}{l}\text { Kelengkapan instrument penggunaan LKS tidak } \\
\text { dicantumkan }\end{array}$ & $\begin{array}{l}\text { Penggunaan LKS telah dicantumkan pada } \\
\text { RPP }\end{array}$ \\
\cline { 2 - 3 } & $\begin{array}{l}\text { Kalimat pembuka pembelajaran awal masih ku- } \\
\text { rang aktif. }\end{array}$ & Kalimat pembuka telah disesuaikan. \\
\hline II & $\begin{array}{l}\text { Penulisan RPP perlu diperbaiki, terutama pada } \\
\text { spasi karena ada beberapa kata yang tidak dispasi. }\end{array}$ & Penulisan RPP telah diperbaiki. \\
\hline
\end{tabular}

\section{Keterlaksanaan pembelajaran}

Dalam penelitian ini, aktivitas guru dalam melaksanakan pembelajaran IPA berbasis kearifan local diamati oleh dua observer yang sudah terlatih. Hasil analisis keterlaksanaan pembelajaran disajikan pada Tabel 4.

Tabel 4. Hasil Keterlaksanaan Pembelajaran

\begin{tabular}{cccc}
\hline Pertemuan & Total skor & Keterlaksanaan & Kategori \\
\hline 1 & 10 & $83,3 \%$ & Sangat baik \\
2 & 11 & $92,0 \%$ & Sangat baik \\
\hline
\end{tabular}

Tabel 4 memperlihatkan guru mampu melaksanakan langkah-langkah pembelajaran IPA berbasis kearifan lokal pada pertemuan 1 dan 2 masing-masing 83,3\% dan 92,0\% dengan kategori sangat baik. Berarti, guru mampu mengintegrasikan kearifan lokal dalam pembelajaran IPA dengan baik. Integrasi ini menjadikan siswa lebih mudah belajar materi IPA dan berkontribusi terhadap peningkatan hasil belajar kognitifnya.

\section{Hasil belajar kognitif siswa}

Keberhasilan guru dalam melaksanakan pembelajaran IPA berbasis kearifan lokal ini ditunjang oleh capaian hasil belajar siswa. Hasil analisis data pre-test dan post-test hasil belajar siswa disajikan pada Tabel 5 .

Tabel 5. Hasil Pre-test dan Post-test Kognitif Siswa

\begin{tabular}{cccccc}
\hline \multirow{2}{*}{ Keterangan } & \multirow{2}{*}{ Pre-test } & Post-test & \multicolumn{2}{c}{ Nilai Rata-rata } & \multirow{2}{*}{ N-Gain } \\
\cline { 4 - 5 } & & 18 & Pre-test & Post-test & \\
Jumlah siswa & 18 & \multirow{2}{*}{32,40} & 76,60 & \multirow{2}{*}{0,64} \\
Nilai tertinggi & 72,30 & 92,50 & & \\
\hline
\end{tabular}




Nilai terendah $\quad 20,00 \quad 45,00$

Berdasarkan Tabel 5; hasil pre-test menunjukkan bahwa kemampuan kognitif siswa pada awalnya masih di bawah kriteria ketuntasan minimum $(\mathrm{KKM}=70)$. Sebaliknya, setelah diterapkan perangkat pembelajaran IPA berbasis kearifan lokal, hasil post-test menunjukkan kemampuan kognitif siswa sudah mencapai KKM. Hal ini diperkuat hasil perhitungan n-gain sebesar 0,64; berarti peningkatan hasil belajar kognitif siswa dalam kategori sedang. Peningkatan ini tidak lepas dari metode atau model yang digunakan oleh guru, di mana guru mampu menggunakan metode diskusi terintegrasi pada tradisi lokal yang telah diketahui oleh siswa sendiri. Siswa mudah mengikuti pelajaran, walaupun pada pertemuan pertama mereka masih kurang berminat dan bingung dengan setiap langkah kegiatan pembelajaran yang dilakukan. Siswa juga lebih termotivasi untuk peduli dengan tradisi yang dimilikinya. Proses pembelajaran IPA dapat dikembangkan dengan bertumpu pada keunikan dan keunggulan suatu daerah (Kartono dkk., 2011). Selain itu, kegiatan diskusi menjadikan aktivitas dan kreativitas siswaclebih tinggi. Aktivitas dan kreativitas siswa lebih tinggi ketika mereka melakukan diskusi atau percobaan dalam kelompok daripada hanya menerima informasi dari ceramah guru (Subagia \& Wiratma, 2008). Melalui integrasi kearifan local dalam pembelajaran IPA; siswa mengembangkan pemahaman diri melalui pembelajaran kontekstual dan secara tidak langsung mampu menumbuhkan kesadaran dan budaya cinta lingkungan (Afdalia dkk., 2020; Utami dkk., 2019).

Pembelajaran IPA berbasis kearifan lokal mampu meningkatkan hasil belajar kognitif siswa dalam kategori sedang. Temuan ini didukung hasil-hasil penelitian sebelumnya bahwa pembelajaran IPA berbasis kearifan lokal dapat meningkatkan hasi belajar kognitif siswa (Fitriani dkk., 2019; Huda dkk., 2020; Mannan, 2015; Pamungkas, 2017). Selain itu, pembelajaran ini mampu meningkatkan capaian nature of science; di mana hasil belajar kognitif siswa yang dilihat dari nilai rata-rata uji gain bernilai positif. Hal ini juga didukung hasil respon positif siswa terhadap kegiatan pembelajaran yang dilakukan. Hasil analisis angket respon siswa disajikan pada Tabel 6 .

\begin{tabular}{cccc}
\multicolumn{4}{c}{ Tabel 6. Hasil Respon Siswa } \\
\hline Jumlah Siswa & Total Skor & Rerata Skor & Kategori \\
\hline 19 & 39,6 & 3,6 & Sangat baik \\
\hline
\end{tabular}

Tabel 6 memperlihatkan bahwa siswa pada umumnya memberikan respon siswa terhadap proses dan kegiatan pembelajaran IPA berbasis kearifan lokal dalam kategori sangat baik. Pada respon ini; siswa memberikan tanggapan dan reaksi terhadap aktivitas pembelajaran yang diikutinya dengan mengisi pertanyaan tertutup yang diberikan (Aisyah, 2016; Sugiyono, 2015). Dalam hal ini, siswa merasa setuju untuk belajar menggunakan perangkat pembelajaran berbasis kearifan lokal yang telah dikembangkan dan mereka memberikan respon yang sangat positif untuk pembelajaran. Berarti, siswa menyukai model pembelajaran yang digunakan. Siswa sudah berani untuk mengajukan pertanyaan dan menyampaikan argumentasinya selama proses pembelajaran di depan kelas. Selain itu, mereka juga terlihat lebih bersemangat dalam mengikuti pembelajaran IPA berbasis kearifan lokal. Hal ini sesuai dengan temuan Afdalia dkk. (2020) bahwa implementasi pembelajaran IPA Fisika berbasis kearifan lokal mendapatkan respon positif dari siswa ditinjau dari segi penggunaannya dalam pembelajaran.

Berdasarkan Tabel 4 s/d 6; perangkat pembelajaran IPA berbasis kearifan local diyakini layak digunakan untuk meningkatkan hasil belajar kognitif siswa dalam kategori sedang. Integrasi kearifan lokal dalam pembelajaran IPA dapat memberikan wawasan pengetahuan bagi para pendidik untuk menanamkan nilai-nilai kearifan lokal dalam pembelajaran IPA (Afdalia dkk., 2020; Huda dkk., 2020). Kearifan lokal menjadikan pembelajaran lebih otentik dan bermakna bagi siswa (Fitriani dkk., 2019). Dengan demikian, implikasi fundamental hasil penelitian ini adalah siswa tidak lagi belajar IPA sebatas pengetahuan, tetapi mereka merasakan pengalaman langsung yang otentik dan bermakna; serta mereka dilibatkan dalam proses berpikir untuk mengonstruksi pengetahuannya sendiri. Namun, kelemahan penelitian ini adalah uji coba penelitian ini masih dalam skala kecil dan dalam waktu yang singkat (160 menit) sehingga tahapan dalam tiap pelajaran kurang maksimal dilakukan. Selain itu, kearifan lokal masih dibatasi pada tradisi saja sehingga berbagai kearifan lokal yang ada belum dapat dimaksimalkan. 
Khaerani, Utami, \& Musrsali. (2020). Pengembangan Perangkat Pembelajaran IPA Berbasis Kearifan Lokal untuk Meningkatkan Hasil Belajar Kognitif Siswa

\section{SIMPULAN}

Hasil pengembangan perangkat pembelajaran IPA berbasis kearifan lokal telah memenuhi kategori valid, fase-fase RPP dapat dilaksanakan dengan baik, dan hasil belajar kognitif siswa dapat meningkat dalam kategori sedang. Selain itu, siswa memberikan respon positif terhadap proses pembelajaran yang telah diikutinya. Dengan demikian, perangkat pembelajaran IPA berbasis kearifan lokal termasuk layak digunakan dalam pembelajaran. Integrasi kearifan lokal dalam pembelajaran IPA menjadikan pembelajaran IPA lebih otentik dan bermakna bagi siswa. Rekomendasi penelitian selanjutnya adalah pelaksanaan pembelajaran minimal 4-5 kali pertemuan agar hasil belajar kognitif siswa lebih maksimal. Selain itu, peneliti perlu memperbanyak kearifan lokalnya agar berbagai kearifan lokal yang ada di lingkungannya dapat dimanfaatkan dengan baik.

\section{DAFTAR PUSTAKA}

Afdalia, A., Arsyad, M., \& Arafah, K. (2020). Pengembangan Modul Pembelajaran IPA Fisika Berbasis Kearifan Lokal Sandeq pada Sekolah Menengah Pertama. Prosiding Seminar Nasional Fisika PPs Universitas Negeri Makassar, Mei 2020.

Aisyah, A., Panjaitan, R. G. P., \& Marlina, R. (2016). Respon Siswa Terhadap Media E Comic Bilingual Sub Materi Bagian-Bagian Darah. Jurnal Pendidikan dan Pembelajaran, 5(3), 1-12.

Depdiknas. (2006). Panduan Pengembangan Pembelajaran IPA Terpadu SMP/MTs. Jakarta: Pusat Kurikulum Badan Penelitian dan Pengembangan, Departemen Pendidikan Nasional.

Fitriani, N., Efendi, I., \& Harisanti, B. M. (2019). Pengembangan Modul Pembelajaran IPA Berbasis Kearifan Lokal Desa Sembalun untuk Peningkatan Hasil Belajar Kognitif Siswa MTs. Bioscientist: Jurnal Ilmiah Biologi, 7(1), 68-78.

Hake, R. R. (1999). Interactive-Engagement vs Traditional Methods, A six-Thousand-Student Survey of Mechanic Test Data for Introductory Physics Course. American Journal of Physics, 66, 6474.

Huda, C., Siswoningsih, D., \& Nuvitalia, D. (2020). Efektivitas Pembelajaran Fisika Menggunakan Modul Sains Berbasis Local wisdom pada pembahasan Suhu dan Kalor. Jurnal Penelitian Pembelajaran Fisika, 11(1), 89-94.

Kartono, H \& Bujang, G. (2011). Penelusuran Budaya dan Teknologi Lokal dalam Rangka Rekonstruksi dan pengembangan Sains di Sekolah. Jurnal Cakrawala Kependidikan, 9(1), 19-26.

Mannan, N. M., Sopyan, A., \& Sunarno. (2015). Pengembangan Perangkat Pembelajaran Berbasis Kearifan Lokal Untuk Mengembangkan Karakter Positif Siswa SD. Jurnal Inovasi Dan Pembelajaran Fisika, 2(2), 141-146.

Martin, M. O, Mullis, I., Foy, P., \& Stanco, G.M. (2012). TIMSS International result in science.

Riduwan. (2005). Skala Pengukuran Variabel-variabel Penelitian. Bandung: Alfabeta

Ridwan, N. A. (2007). Landasan Keilmuan Kearifan Lokal. Jurnal Studi Islam dan Budaya, 5(1), $27-$ 38.

Saputra. A., Wahyuni .S., \& Handayani. D. R. (2016). Pengembangan Modul IPA Berbasis Kearifan Lokal Daerah Pesisir Puger Pada Pokok Bahasan Sistem Transportasi Di SMP. Jurnal Pembelajaran Fisika, 5(2), 182-189

Suastra, I. W., Tika, K., \& kariasa, N. (2011). Efektivitas Model Pembelajaran Sains Berbasis Budaya Lokal untuk Mengembangkan Kompetensi dasar sains dan Nilai kearifan Lokal di SMP. JPPP Lemlit, 5(3), 258-273.

Subagia, I. W., \& Wiratma, I. G. L. (2008). Penerapan Model Siklus Belajar Berbasis Tri Pramana Pada Pembelajaran Sains di Sekolah. Jurnal Pendidikan Dan Pengajaran Undiksha, 42(2), 8996.

Sugiyono. (2015). Metode Penelitian Kuantitati Kualitatif dan R\&D. Bandung: Alfabeta.

Utami, S. D \& Dewi, I. N. (2017). Validitas Perangkat Pemelajaran Biologi Terintegrasi Kearifan Lokal Untuk Mengembangkan Keterampilan Penyelesaian Masalah Mahasiswa. Jurnal Ilmiah Pendidikan Biologi "Bioscientist," 5(2), 40-44.

Utami, S. D., Efendi, I., Dewi, I. N., Ramdani, A., \& Rohyani, I. S. (2018, July). The Study of Local Wisdom of Ethnic Sasaks in Development of Biology Instructional Learning Program (P3Bio) Based on 21st Century Skills. In Mathematics, Informatics, Science, and Education International Conference (MISEIC 2018). Atlantis Press. 
Utami, S. D., Efendi, I., Dewi, I. N., Ramdani, A., \& Rohyani, I.S. (2019). Perangkat Pembelajaran Etnoekologi masyarakat Suku Sasak Kawasan Taman Nasionnal Gunung Rinjani. Jurnal Penelitian Pendidikan IPA, 5 (2), 240-247.

Widoyoko. (2012). Teknik Penyusunan Instrument Penelitian.Yogyakarta: Pustaka Belajar.

Wilujeng. I., Kun. Z. P., \& Suryadarma, I. G. P. (2016). Pengembangan Perangkat Pembelajaran IPA Berbasis Potensi Lokal untuk meningkatkan Capaian Nature of Science (NOS). Diakses melalui https://core.ac.uk/download/pdf/83146473.pdf. 
Khaerani, Utami, \& Musrsali. (2020). Pengembangan Perangkat Pembelajaran IPA Berbasis Kearifan Lokal untuk Meningkatkan Hasil Belajar Kognitif Siswa 